\title{
High-sensitive C-reactive protein is associated with reduced lung function
} in young adults

\author{
F. Rasmussen*, D. Mikkelsen\#, R.J. Hancox, J. Lambrechtsen+, M. Nybo ${ }^{\S}$, \\ H.S. Hansen ${ }^{\#}$ and H.C. Siersted*
}

ABSTRACT: Systemic inflammation has been associated with reduced lung function. However, data on the interrelationships between lung function and inflammation are sparse, and it is not clear if low-grade inflammation leads to reduced lung function.

Associations between high-sensitive C-reactive protein (CRP) and spirometric lung function were assessed in a population-based cohort of $\sim 1,000$ Danes aged 20 yrs.

In males, the average decline in forced expiratory volume in one second (FEV 1 ) in the highest CRP quintile was $23 \mathrm{~mL} \cdot \mathrm{yr}^{-1}$ versus $1.6 \mathrm{~mL} \cdot \mathrm{yr}^{-1}$ in the lowest quintile. In females, the average decline was $6.2 \mathrm{~mL} \cdot \mathrm{yr}^{-1}$ in the highest CRP quintile versus an increase of $1.8 \mathrm{~mL} \cdot \mathrm{yr}^{-1}$ in the lowest CRP quintile. In a multiple regression analysis adjusted for sex, body mass index, cardiorespiratory fitness, smoking, asthma, airway hyperresponsiveness and serum eosinophil cationic protein, higher levels of CRP at age 20 yrs were associated with a greater reduction in both FEV 1 and forced vital capacity between ages 20 and 29 yrs.

The findings show that higher levels of $\mathrm{C}$-reactive protein in young adults are associated with subsequent decline in lung function, suggesting that low-grade systemic inflammation in young adulthood may lead to impaired lung function independently of the effects of smoking, obesity, cardiorespiratory fitness, asthma and eosinophilic inflammation.

KEYWORDS: Cohort studies, C-reactive protein, fitness, inflammation, lung function

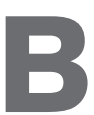
lood C-reactive protein (CRP), a marker of systemic inflammation, has consistently been found to be associated with excess mortality and adverse cardiovascular outcomes independently of confounding factors such as age and smoking [1]. Increased systemic inflammation has also been shown to be associated with lower spirometric lung function [2]. Moreover, a low spirometry value not only predicts mortality from respiratory disease but is also a risk factor for all-cause mortality [3]. This raises the possibility that the association between poor lung function and mortality may be mediated by an inflammatory mechanism.

The interrelationships between reduced lung function and inflammation is poorly understood. Smoking, asthma and airway hyperresponsiveness (AHR) are all associated with decline in lung function [4,5] and, while smoking is associated with increased CRP levels [6], it seems that asthma and AHR influence lung function through other pathways [7]. Obesity and poor cardiorespiratory fitness are other factors that are associated with higher CRP levels [8] and reduced lung function and could possibly help to explain these associations [9]. The temporal relationship between systemic inflammation and poor lung function is also unclear. Although several studies have explored this association [1, 10-15], each of these studies had certain limitations. Some of these studies were cross sectional in nature and unable to assess the temporal relationships [10, 11]. Longitudinal studies have found that lung function decline was associated with raised levels of CRP at follow-up, but found little or no evidence that high levels of CRP predicted a subsequent decline in lung function. However, these studies have mostly been conducted in middle-aged individuals [13] or elderly subjects [1, 15]; highsensitivity CRP measurements were not used on both occasions and the influence of low-grade inflammation may have been missed $[12,14]$.

\section{AFFILIATIONS}

Depts of *Respiratory Diseases,

\#Cardiology, and

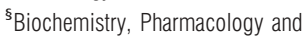

Genetics, Odense University Hospital, Odense,

${ }^{+}$Dept of Medicine, Svendborg Hospital, Svendborg, Denmark. "Dunedin Multidisciplinary Health and Development Research Unit, Dunedin School of Medicine, University of Otago, Dunedin, New Zealand.

CORRESPONDENCE

F. Rasmussen

Dept of Respiratory Diseases

Odense University Hospital

5000 Odense C

Denmark

Fax: 4565412728

E-mail: Finn.Rasmussen@dadlnet.dk

Received:

March 172008

Accepted after revision:

September 272008

SUPPORT STATEMENT

The study was supported by the Danish Lung Association, the Danish Medical Research Council, the University of Southern Denmark, Odense University, the Hørslev Foundation and Else and Mogens Wedell-Wedellsborg Foundation (all Copenhagen, Denmark).

\section{STATEMENT OF INTEREST}

None declared. 
The present study explored the temporal relationships between changes in lung function decline and CRP levels using high-sensitivity assays in a population-based cohort study of young adults. It was hypothesised that high levels of CRP would be associated with the subsequent decline in lung function after adjusting for the potential confounding influences of body mass index (BMI), cardiorespiratory fitness, smoking, asthma, AHR and serum eosinophil cationic protein (ECP) as a marker of eosinophilic inflammation.

\section{METHODS}

Additional details regarding the methods are provided in the online supplementary material.

\section{Population}

The Odense Schoolchild Study is a prospective communitybased study of a cohort of 1,369 schoolchildren first investigated during their third grade in 1985 . The recruitment of the cohort is described in detail elsewhere [16]. The present report uses data collected at ages 20 and 29 yrs. At age 20 yrs 1,134 (84\%) out of 1,348 eligible subjects, and at age 29 yrs $976(73 \%)$ out of 1,338 eligible subjects were assessed. A total of $870(65 \%)$ subjects were seen at both time-points and, of these, 705 (53\%) had full laboratory data. The subjects had mean ages of 20.1 and 29.3 yrs with a mean follow-up period of 9.2 yrs. No significant differences were found between the baseline characteristics (at age $9 \mathrm{yrs}$ ) of those who did and did not participate in these follow-up assessments (see online supplementary material). All subjects gave informed consent before participating. The study was approved by the local research ethics committee for Vejle and Fyns County (Odense, Denmark) and the Danish Data Surveillance Authority (Copenhagen, Denmark).

\section{Questionnaires}

Asthma diagnosis was defined by the question "Have you been told by a doctor that you have asthma?" Tobacco smokers were defined as those who admitted smoking one or more cigarettes daily for $\geqslant 1 \mathrm{yr}$ at age $\geqslant 20 \mathrm{yrs}$.

\section{Pulmonary function tests}

Forced expiratory volume in one second (FEV1) and forced vital capacity (FVC) were measured using a pneumotachometer (Vitalograph Compact, Buckingham, UK) as previously described [17]. Methacholine provocation tests were performed using an inhalation-triggered dosimeter (ME.FAR MB3 dosimeter; ME.FAR, Medicali, Brescia, Italy) at age $20 \mathrm{yrs}$ [17]. The test results were expressed as a dose-response slope according to the method of O'CONNOR et al. [18]. AHR was defined as greater than the value delimiting the $5 \%$ with the highest fall in FEV1 among never-smoking subjects with no previous history of asthma or asthma-like symptoms [19]. The upper 5th percentile in the reference group was $0.68 \%$ per $\mu$ mol. Predicted values of FEV1 and FVC were calculated by sex-specific linear regression equations derived from the same reference study members.

\section{Cardiorespiratory fitness}

Cardiorespiratory fitness was measured at both assessments using the same maximal progressive exercise test on an electrically braked cycle ergometer. The workload was increased every $3 \mathrm{~min}$ by increments based on the subject's weight and exercise data from a questionnaire. Subjects were encouraged to provide maximal effort; effort was accepted as maximal when the subject exceeded $85 \%$ of their expected maximal heart rate, which was calculated as 220 minus age in years. Cardiorespiratory fitness was measured as the maximum workload $\left(\mathrm{W} \cdot \mathrm{kg}^{-1}\right)$ attained. This test has been shown to provide an accurate and valid estimate of maximal oxygen consumption [20].

\section{Blood sampling}

Blood samples at ages 20 and 29 yrs were collected and analysed at the Dept of Biochemistry, Pharmacology and Genetics, Odense University Hospital (Odense, Denmark). Samples were stored at $-70^{\circ} \mathrm{C}$ until analysed. ECP at age $20 \mathrm{yrs}$ was analysed as previously reported [17]. CRP was analysed on a Modular Analytics P (Roche Diagnostics, Rotkreuz, Switzerland) using a particle-enhanced turbidimetric immunoassay. The lower limit of detection was $0.03 \mathrm{mg} \cdot \mathrm{L}^{-1}$. The intra- and interassay variations were $0.43 \%$ and $2.1 \%$, respectively.

\section{Statistical methods}

Differences in dichotomous and in continuously distributed variables were evaluated using Chi-squared and t-tests (both paired and unpaired), respectively. Two-tailed tests were used with a 5\% significance level. Arithmetic means (and 95\% confidence intervals (CIs)) of each variable were calculated, except for CRP and ECP levels, which had skewed distributions and were log-transformed before analysis. These values were transformed back to geometric means and 95\% CIs.

To test the hypothesis that systemic inflammation leads to decline in lung function, multiple linear regression (entry method) was used to assess the associations of log-CRP (at age $20 \mathrm{yrs}$ ) with lung function at age 29 yrs (FEV1, FVC and FEV1/FVC) and the change in FEV1 and FVC between ages 20 and 29 yrs. These analyses adjusted for sex, height, log-ECP, asthma, cardiorespiratory fitness, smoking and BMI at 20 yrs. The analysis used absolute values of lung function and adjusted for height in the analysis rather than using \% predicted values [21]. BMI was categorised as $<25 \mathrm{~kg} \cdot \mathrm{m}^{-2}$ (normal), $\geqslant 25$ and $<30 \mathrm{~kg} \cdot \mathrm{m}^{-2}$ (overweight) and $\geqslant 30 \mathrm{~kg} \cdot \mathrm{m}^{-2}$ (obese) to avoid possible collinearity with cardiorespiratory fitness in the regression equations (repeat analyses using BMI as a continuous variable did not change the results).

To test the alternative hypothesis that the decline in FEV1 leads to an increase in systemic inflammation, multiple linear regression was used to test whether the change in FEV1 between ages 20 and $29 \mathrm{yrs}$ predicted log-CRP at $29 \mathrm{yrs}$, adjusting for the same potential confounding variables.

The linearity assumptions of the models were checked by fitting quadratic and cubic terms for log-CRP.

Pregnant females were excluded from all analyses (age 20 yrs, $\mathrm{n}=3 ; 29$ yrs, $\mathrm{n}=38$ ).

\section{RESULTS}

CRP levels, lung function, BMI, cardiopulmonary fitness, asthma and smoking findings from subjects aged 20 and 29 yrs are shown in table 1. CRP levels increased between these ages in males but not in females. Despite this, CRP levels 
TABLE 1 Characteristics of males and females at ages 20 and $29 \mathrm{yrs}$



Data are presented as mean (95\% confidence interval), unless otherwise stated. Pregnant females were excluded. CRP: C-reactive protein; FEV 1 : forced expiratory volume in one second; FVC: forced vital capacity; \% pred: \% predicted; BMI: body mass index. ${ }^{\#}: n=344 ;{ }^{\bullet}: n=323{ }^{+}{ }^{+}$geometric mean.

TABLE 2 Adjusted associations of risk factors with forced expiratory volume in one second (FEV1), forced vital capacity (FVC) and FEV1/FVC at age $29 \mathrm{yrs}$ and change in FEV1, FVC and FEV1/FVC between ages 20 and $29 \mathrm{yrs}$

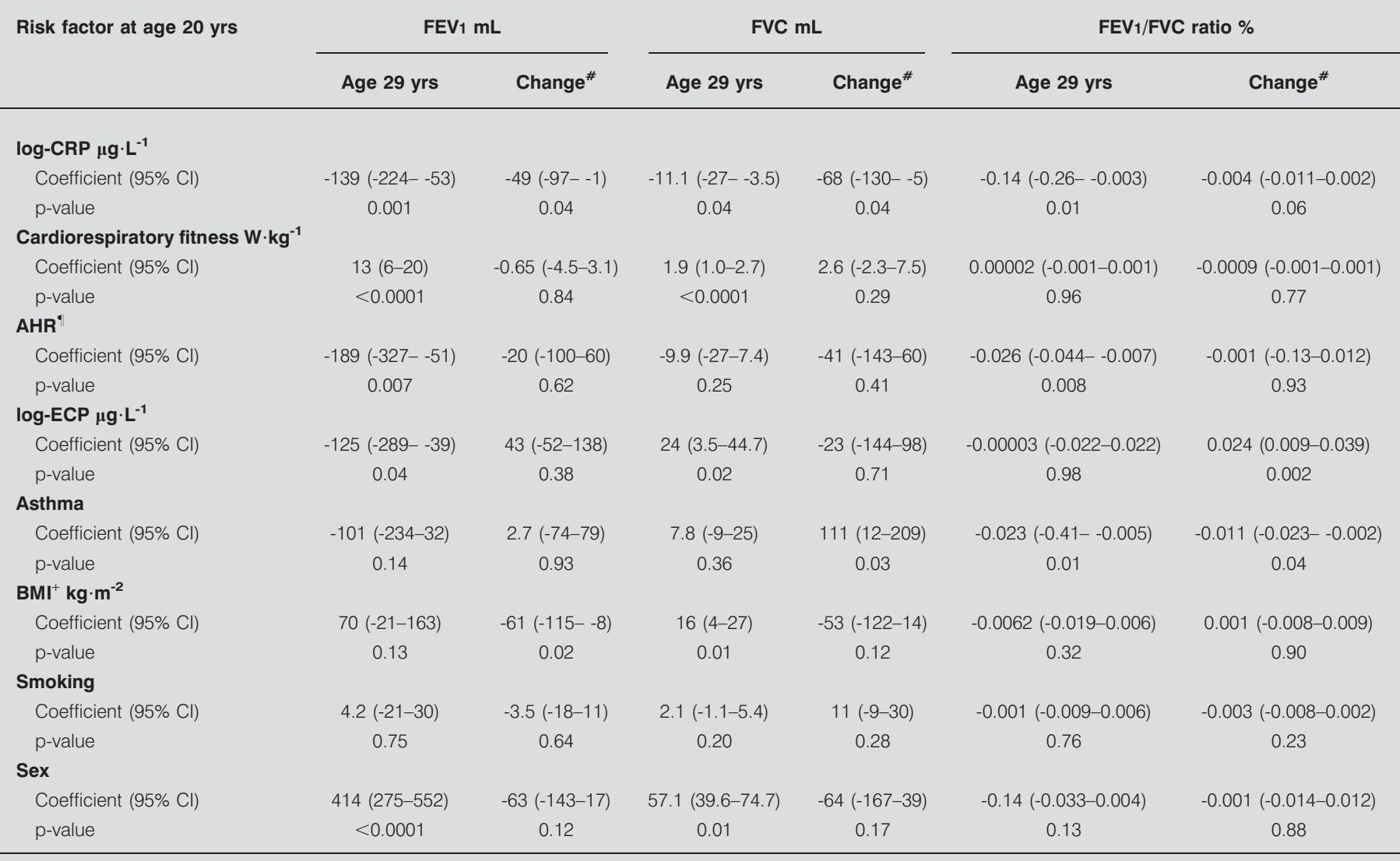

Coefficients were adjusted for all factors tabulated and height. CRP: C-reactive protein; Cl: confidence interval; AHR: airway hyperresponsiveness; ECP: eosinophil cationic protein; BMI: body mass index. ${ }^{*}$ : between ages 20 and $29 \mathrm{yrs}^{\circ}{ }^{*}$ : expressed as a dose-response slope, and defined as greater than the value delimiting the $5 \%$ with the highest fall in FEV1 among never-smoking subjects with no previous history of asthma or asthma-like symptoms (the upper 5th percentile in the reference group was $0.68 \%$ per $\mu \mathrm{mol}){ }^{+}$: normal $<25 \mathrm{~kg} \cdot \mathrm{m}^{-2}$, overweight $\geqslant 25 \mathrm{~kg} \cdot \mathrm{m}^{-2}$ and $<30 \mathrm{~kg} \cdot \mathrm{m}^{-2}$, and obese $\geqslant 30 \mathrm{~kg} \cdot \mathrm{m}^{-2}$. 


\begin{tabular}{|c|c|c|c|}
\hline TABLE 3 & \multicolumn{3}{|c|}{$\begin{array}{l}\text { Adjusted associations of risk factors with C- } \\
\text { reactive protein (CRP) at age } 29 \text { yrs and change } \\
\text { in CRP between ages } 20 \text { and } 29 \text { yrs }\end{array}$} \\
\hline \multirow{2}{*}{\multicolumn{2}{|c|}{ Risk factor at age $20 \mathrm{yrs}$}} & \multicolumn{2}{|c|}{ CRP $\mu \mathrm{g} \cdot \mathrm{L}^{-1}$} \\
\hline & & Age $29 \mathrm{yrs}$ & Change $^{\#}$ \\
\hline \multicolumn{4}{|l|}{ FEV1 } \\
\hline \multicolumn{2}{|c|}{ Coefficient $(95 \%$ Cl) } & $0.16(-0.12-0.84)$ & $0.095(-0.21-0.21)$ \\
\hline \multicolumn{2}{|l|}{$p$-value } & 0.76 & 0.10 \\
\hline \multicolumn{4}{|l|}{$\mathbf{W} \cdot \mathbf{k g}^{-1}$} \\
\hline \multicolumn{2}{|c|}{ Coefficient (95\% Cl) } & $-0.0059(-0.13--0.001)$ & $0.0074(0.001-0.016)$ \\
\hline \multicolumn{2}{|l|}{$\mathrm{p}$-value } & 0.05 & 0.04 \\
\hline \multicolumn{4}{|l|}{ AHR ${ }^{\circ}$} \\
\hline \multicolumn{2}{|c|}{ Coefficient $(95 \% \mathrm{Cl})$} & $0.17(0.02-0.32)$ & $-0.038(-0.22-0.13)$ \\
\hline \multicolumn{2}{|l|}{$p$-value } & 0.02 & 0.66 \\
\hline \multicolumn{4}{|l|}{$\mathrm{ECP} \mu \mathrm{g} \cdot \mathrm{L}^{-1}$} \\
\hline \multicolumn{2}{|c|}{ Coefficient $(95 \% \mathrm{Cl})$} & $0.093(-0.79-0.27)$ & $-0.24(-0.44-0.30)$ \\
\hline \multicolumn{2}{|l|}{$p$-value } & 0.28 & 0.12 \\
\hline \multicolumn{4}{|l|}{ Asthma } \\
\hline \multicolumn{2}{|c|}{ Coefficient $(95 \% \mathrm{Cl})$} & $-0.090(-0.23-0.053)$ & $0.049(-0.12-0.22)$ \\
\hline \multicolumn{2}{|l|}{$p$-value } & 0.22 & 0.56 \\
\hline \multicolumn{4}{|l|}{$\mathrm{BMI}^{+} \mathbf{k g} \cdot \mathrm{m}^{-2}$} \\
\hline \multicolumn{2}{|c|}{ Coefficient $(95 \% \mathrm{Cl})$} & $0.22(0.13-0.32)$ & $0.12(0.001-0.23)$ \\
\hline \multicolumn{2}{|l|}{$p$-value } & $<0.0001$ & 0.04 \\
\hline \multicolumn{4}{|l|}{ Smoking } \\
\hline \multicolumn{2}{|c|}{ Coefficient $(95 \%$ Cl) } & $-0.02(-0.079-0.039)$ & $-0.24(-0.99-0.45)$ \\
\hline \multicolumn{2}{|l|}{$\mathrm{p}$-value } & 0.51 & 0.50 \\
\hline \multicolumn{4}{|l|}{ Sex } \\
\hline \multicolumn{2}{|c|}{ Coefficient $(95 \% \mathrm{Cl})$} & $-0.11(-0.26-0.039)$ & $-0.43(-0.62-0.14)$ \\
\hline \multicolumn{2}{|l|}{$p$-value } & 0.15 & 0.66 \\
\hline
\end{tabular}

Coefficients were adjusted for all factors tabulated and height. FEV1: forced expiratory volume in one second; $\mathrm{Cl}$ : confidence interval; AHR: airway hyperresponsiveness; ECP: eosinophil cationic protein; BMI: body mass index. \#: between ages 20 and $29 \mathrm{yrs}$; ": expressed as a dose-response slope, and defined as greater than the value delimiting the $5 \%$ with the highest fall in FEV 1 among never-smoking subjects with no previous history of asthma or asthmalike symptoms (the upper 5 th percentile in the reference group was $0.68 \%$ per $\mu \mathrm{mol}$ ); ${ }^{+}$: normal $<25 \mathrm{~kg} \cdot \mathrm{m}^{-2}$, overweight $\geqslant 25 \mathrm{~kg} \cdot \mathrm{m}^{-2}$ and $<30 \mathrm{~kg} \cdot \mathrm{m}^{-2}$, and obese $\geqslant 30 \mathrm{~kg} \cdot \mathrm{m}^{-2}$

were higher in females than in males at both ages. The sexadjusted partial correlation coefficient between CRP measurements at ages 20 and 29 yrs was $r=0.39(p<0.001)$.

Higher levels of log-CRP at 20 yrs were associated with lower values of FEV1, FVC and FEV1/FVC ratio at age $29 \mathrm{yrs}$, and greater declines in FEV1 and FVC between 20 and 29 yrs, after controlling for cardiorespiratory fitness, BMI, AHR, ECP, asthma, smoking, sex and height at $20 \mathrm{yrs}$ (table 2). The association between log-CRP at age 20 yrs and the change in FEV1/FVC ratio between ages 20 and $29 \mathrm{yrs}$ did not reach formal significance $(p=0.06)$.

FEV1 at 20 yrs did not predict the level of CRP at 29 yrs or the change in CRP between ages 20 and 29 yrs (table 3). When the change in FEV1 between 20 and 29 yrs was used as the independent (predictor) variable in the regression, a significant association was found with CRP at age 29 yrs $(\mathrm{p}<0.0001)$ and a trend towards an association with the change in CRP between ages 20 and 29 yrs $(p=0.09)$. Stratification for sex or smoking did not alter the regression results (data not shown).

The average change in FEV1 was -23 versus $-1.6 \mathrm{~mL} \cdot \mathrm{yr}^{-1}$ in the highest and lowest CRP quintiles, respectively, in males $(\mathrm{p}<0.0001)$ and -6.2 versus $1.8 \mathrm{~mL} \cdot \mathrm{yr}^{-1}$ in the highest and lowest CRP quintiles, respectively, in females $(p=0.25$; further data are provided in the online supplementary material). In order to assess whether this association was likely to be due to respiratory disease, the changes in lung function between ages 20 and $29 \mathrm{yrs}$ and the FEV1/FVC ratio at $29 \mathrm{yrs}$ were compared according to CRP quintiles at $20 \mathrm{yrs}$ for nonasthmatic, nonsmoking participants without respiratory symptoms. While no significant associations were seen in females (data not shown), higher levels of CRP at age 20 yrs were significantly associated with decline in FEV1 in males (fig. 1). CRP levels at 20 yrs did not predict the change in the FEV1/ FVC ratio, but there was a trend towards an association with lower FEV1/FVC ratios at age 29 yrs.

The change in FEV1 between ages 20 and 29 yrs among nonasthmatic, nonsmoking males without respiratory symptoms was associated with CRP values at age 29 yrs $(p<0.0001)$, but not with changes in CRP values between ages 20 and 29 yrs ( $\mathrm{p}=0.29$; fig. 2$)$.

Excluding subjects with very high CRP levels $\left(>10 \mathrm{mg} \cdot \mathrm{L}^{-1}\right)$ and a split half of the data to test the stability of regression equations did not change the findings (these were performed for all regressions).

\section{DISCUSSION}

The relationship between blood CRP and lung function in an unselected cohort of young adults was investigated at ages 20 and 29 yrs. It was found that higher levels of CRP at $20 \mathrm{yrs}$ predicted the subsequent decline in lung function by age $29 \mathrm{yrs}$. This association was independent of smoking, BMI, cardiorespiratory fitness, AHR, asthma and serum ECP. The findings indicate that there is an association between systemic inflammation and the decline in lung function that is not explained by asthma, smoking-related lung disease, poor fitness or obesity.

Cross-sectional associations between poor lung function and CRP have previously been shown in chronic obstructive pulmonary disease patients [22-24] and in healthy subjects $[2,13-15,25]$. Longitudinal studies have also demonstrated that the decline in lung function predicts CRP levels at followup $[14,15]$. However, the present study is the first to show an association between CRP and subsequent decline in lung function. In contrast, neither the longitudinal study of young adults by HANCOX et al. [14] nor the study of older adults by FOGARTY et al. [15] found that CRP levels predicted the subsequent decline in lung function. This might be because HANCOX et al. [14] used a low-sensitivity CRP assay in their initial assessments of subjects in their population-based cohort from New Zealand. The main difference between the present study and that of FOGARTY et al. [15] is age of the subjects. The latter study used a very wide age range (18-70 yrs), with $70 \%$ being aged $>40$ yrs at baseline and relatively few subjects aged $<30$ yrs. It is also possible that that study may have been biased by survival. In accordance with the present findings, 

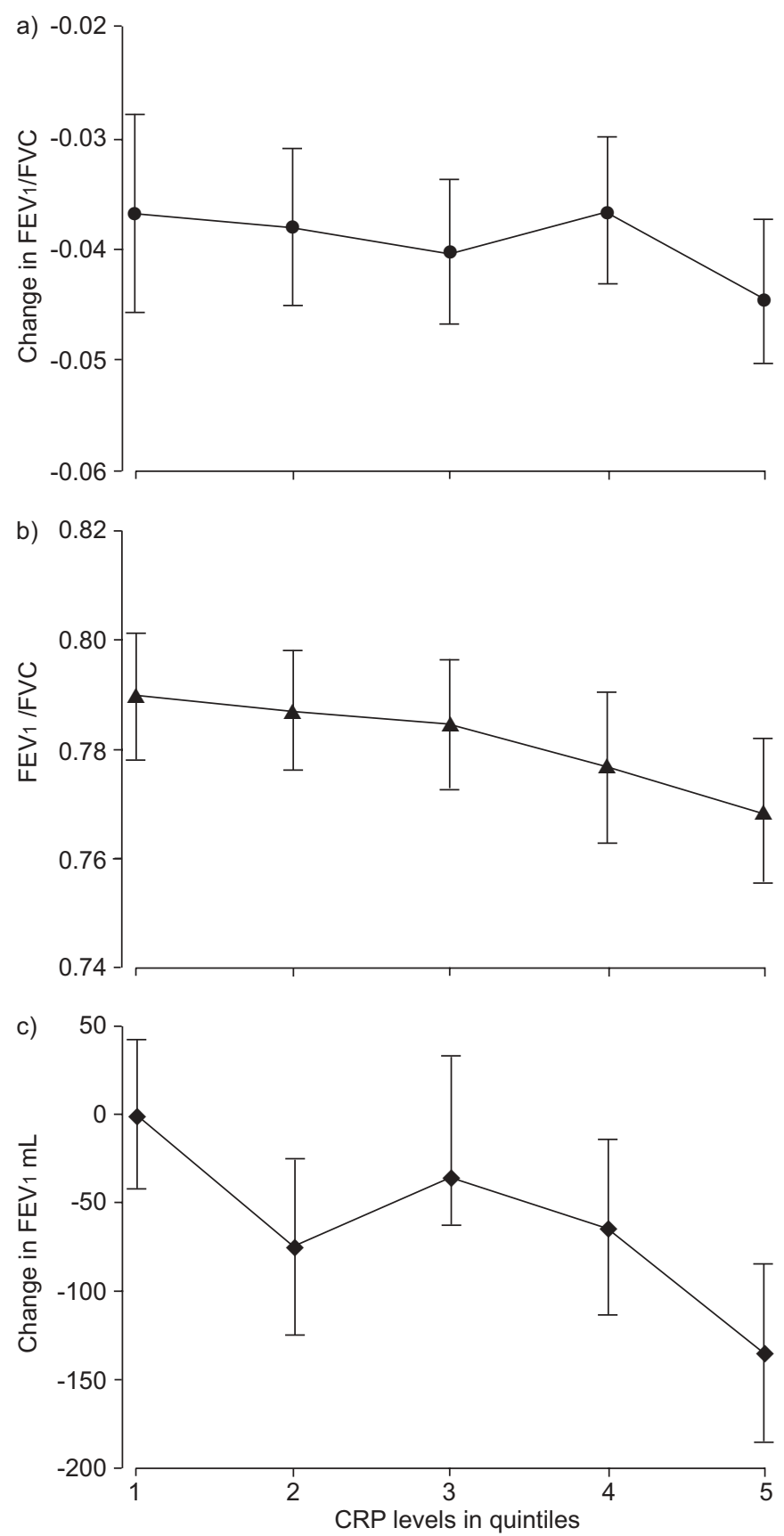

FIGURE 1. Relationship between high-sensitive C-reactive protein (CRP) levels (in quintiles) at age $20 \mathrm{yrs}$ and a) change in forced expiratory volume in one second ( $F E V_{1}$ )/forced vital capacity (FVC) ratio between the ages of 20 and $\left.29 \mathrm{yrs}, \mathrm{b}\right) \mathrm{FEV} 1 /$ FVC at age $29 \mathrm{yrs}$, and c) change in FEV1 between the ages of 20 and $29 \mathrm{yrs}$. a) $p=0.36$; b) $p=0.07$; c) $p=0.004$.

SHAABAN et al. [13] found an association between CRP at baseline and a decline in FEV1 in middle-aged subjects (average age $37 \mathrm{yrs}$ ) over a follow-up period of $8.5 \mathrm{yrs}$, although this association did not reach formal significance $(p=0.07)$. Additionally, plasma fibrinogen, another marker of systemic inflammation, was found to predict subsequent lung function decline in a 5-yr follow-up study of young American adults [12]. This indicates that different markers of systemic inflammation may be similar in predicting changes in lung


FIGURE 2. Relationship between mean change in forced expiratory volume in one second (FEV1) between the ages of 20 and $29 \mathrm{yrs}$ (in quintiles) and a) change in C-reactive protein (CRP) levels between the ages of 20 and $29 \mathrm{yrs}$, and b) CRP level at age 29 yrs. a) $p=0.29$; b) $p<0.001$

function. Although the current authors found a trend towards an association between inflammation and FEV1 and FVC decline in both sexes, this was only significant in males in the stratified analysis (see online supplementary data). A similar sex difference in the association between lung function decline and CRP levels at follow-up has been reported from the European Community Respiratory Health Survey [26], and these findings suggest that there may be a sex difference in the pulmonary response to systemic inflammation.

The association between CRP at 20 yrs and subsequent change in FEV1/FVC ratio did not reach formal statistical significance $(p=0.06)$. Thus, although systemic inflammation predicts lung function decline, it remains uncertain whether it is a risk factor for the development of airflow obstruction in young adults. Further studies with a longer follow-up are needed to confirm this.

CRP is produced primarily in the liver in response to interleukin (IL)-6, and its concentration has consistently been shown to be related to increased cardiovascular risk [1]. Studies suggest that individuals who are able to produce high levels of IL-6 are disadvantaged for longevity [27]. In the present cohort, CRP levels increased from the age of 20 to 29 yrs in males, but there was no significant change in females. This may be partly explained by the bigger change in factors known to increase CRP 
levels, such as BMI, blood pressure, cardiorespiratory fitness and cholesterol in males, together with a more pronounced decrease in smoking among females between baseline and follow-up. Despite this, CRP levels in females remained higher than in males. A recent study found that BMI was the strongest clinical predictor of CRP levels [28]. Furthermore, ARONSON et al. [29] found that smoking and metabolic perturbations, cardiorespiratory fitness, BMI, cholesterol and blood pressure are separate and largely independent factors in the pathophysiology of chronic, low-grade inflammation. In light of these observations, it is not surprising that BMI and cardiorespiratory fitness predicted CRP change, whereas lung function did not. The current authors. also found that BMI and cardiorespiratory fitness were associated with lung function values, although only BMI was significantly associated with the decline in lung function. Thus, it is possible that BMI and cardiorespiratory fitness influence lung function indirectly via CRP.

The associations between CRP and lung function were independent of asthma, AHR and serum ECP. A more direct assessment of airway inflammation than ECP would have been preferable (e.g. pathological biopsies) but for obvious reasons these are not suitable in a large epidemiological study. However, the current authors have previously shown that ECP is a risk factor for asthma development [17]. Asthma and ECP were also associated with decline in the FEV1/FVC ratio. Therefore, the present data suggest that the association between a high CRP and decline in lung function is unlikely to be mediated through immunopathological mechanisms associated with asthma or allergic respiratory disease.

The strengths of the present study include: an unselected population-based cohort of young adults who were all of the same age; repeated assessments using the same methods; objective measures of physical fitness and BMI; controlling for smoking; and several markers for ongoing asthma/eosinophilinduced inflammation. Although the rate of participation in the study $(\sim 70 \%)$ is acceptable for a longitudinal study over a period of $9.2 \mathrm{yrs}$, a selection bias is possible. However, comparisons of participating and nonparticipating subjects identified no obvious differences between these two groups (see online supplementary material). As in previous studies, only two time-points were used, which limits the capacity to unravel a temporal sequence in which the temporal relationship between variables is complex or even bidirectional. Furthermore, there are likely to be other important factors that may influence CRP or lung function that were not measured, such as diet, hormonal contraceptive use, vitamins and environmental exposures.

In summary, a significant association between higher levels of C-reactive protein and subsequent decline in lung function has been identified in young adults independently of sex, smoking, asthmatic inflammation, body mass index and cardiorespiratory fitness. These findings suggest that low-grade systemic inflammation early in adult life may lead to a decline in lung function.

\section{ACKNOWLEDGEMENTS}

The authors would like to thank the study members and families of the Odense schoolchild study for their continuing support, and P. Venge (Uppsala University, Uppsala, Sweden) who kindly analysed eosinophil cationic protein.

\section{REFERENCES}

1 Tice JA, Browner W, Tracy RP, Cummings SR. The relation of C-reactive protein levels to total and cardiovascular mortality in older U.S. women. Am J Med 2001; 114: 199-205.

2 Yende S, Waterer GW, Tolley EA, et al. Inflammatory markers are associated with ventilatory limitation and muscle dysfunction in obstructive lung disease in well functioning elderly subjects. Thorax 2006; 61: 10-16.

3 Schroeder EB, Welch VL, Couper D, et al. Lung function and incident coronary heart disease: The Atherosclerosis Risk in Communities Study. Am J Epidemiol 2003; 158: 1171-1181.

4 Lange P, Parner J, Vestbo J, Schnohr P, Jensen G. A 15-year follow-up study of ventilatory function in adults with asthma. N Engl J Med 1998; 339: 1194-1200.

5 Rijcken B, Schouten JP, Xu X, Rosner B, Weiss ST. Airway hyperresponsiveness to histamine associated with accelerated decline in FEV1. Am J Respir Crit Care Med 1995; 151: 1377-1382.

6 Gan WQ, Man SFP, Sin DD. The interactions between cigarette smoking and reduced lung function on systemic inflammation. Chest 2005; 127: 558-564.

7 Boulet LP, Chakir J, Dube J, Laprise C, Boutet M, Laviolette M. Airway inflammation and structural changes in airway hyper-responsiveness and asthma: an overview. Can Respir J 1998; 5: 16-21.

8 Williams MJ, Milne BJ, Hancox RJ, Poulton R. C-reactive protein and cardiorespiratory fitness in young adults. Eur J Cardiovasc Prev Rehabil 2005; 12: 216-220.

9 Jakes RW, Day NE, Patel B, et al. Physical inactivity is associated with lower forced expiratory volume in 1 second: European Prospective Investigation into Cancer Norfolk Prospective Population Study. Am J Epidemiol 2002; 156: 139-147.

10 Engstrom G, Lind P, Hedblad B, et al. Lung function and cardiovascular risk: relationship with inflammation-sensitive plasma proteins. Circulation 2002; 106: 2555-2560.

11 Kony S, Zureik M, Driss F, Neukirch C, Leynaert B, Neukirch F. Association of bronchial hyperresponsiveness and lung function with C-reactive protein (CRP): a population based study. Thorax 2004; 59: 892-896.

12 Thyagarajan B, Jacobs DR, Apostol GG, Smith LJ, Lewis CE, Williams OD. Plasma fibrinogen and lung function: the CARDIA Study. Int J Epidemiol 2006; 35: 1001-1008.

13 Shaaban R, Kony S, Driss F, et al. Change in C-reactive protein levels and FEV1 decline: a longitudinal populationbased study. Respir Med 2006; 100: 2112-2120.

14 Hancox RJ, Poulton R, Greene JM, et al. Systemic inflammation and lung function in young adults. Thorax 2007; 62: 1064-1068.

15 Fogarty AW, Jones S, Britton JR, Lewis SA, McKeever TM. Systemic inflammation and decline in lung function in a general population: a prospective study. Thorax 2007; 62: 515-520.

16 Hansen HS, Hyldebrandt N, Nielsen JR, Froberg K. Blood pressure distribution in a school-age population aged 8-10 years: the Odense Schoolchild Study. J Hypertens 1990; 8: 641-646.

17 Rasmussen F, Lambrechtsen J, Siersted HC, Hansen HS, Hansen NC. Increased eosinophil cation protein level in sensitized nonasthmatics is linked to subsequent 
hyperresponsiveness to methacholine. The Odense Schoolchild Study. Int Arch Allergy Immunol 2000; 121: 129-136.

18 O'Connor G, Sparrow D, Taylor D, Segal M, Weiss S. Analysis of dose-response curves to methacholine. An approach suitable for population studies. Am Rev Respir Dis 1987; 136: 1412-1417.

19 Godfrey S, Springer C, Noviski N, Maayan C, Avital A. Exercise but not methacholine differentiates asthma from chronic lung disease in children. Thorax 1991; 46: 488-492.

20 Hansen HS, Froberg K, Nielsen JR, Hyldebrandt N. A new approach to assessing maximal aerobic power in children: the Odense School Child Study. Eur J Appl Physiol Occup Physiol 1989; 58: 618-624.

21 Vollmer WM, Johnson LR, McCamant LE, Buist AS. Methodologic issues in the analysis of lung function data. J Chronic Dis 1987; 40: 1013-1023.

22 Gan WQ, Man SFP, Senthilselvan A, Sin DD. Association between chronic obstructive pulmonary disease and systemic inflammation: a systematic review and a metaanalysis. Thorax 2004; 59: 574-580.

23 Broekhuizen R, Wouters EFM, Creutzberg EC, Schols AMWJ. Raised CRP levels mark metabolic and functional impairment in advanced COPD. Thorax 2006; 61: 17-22.
24 Pinto-Plata VM, Mullerova $\mathrm{H}$, Toso JF, et al. C-reactive protein in patients with COPD, control smokers and nonsmokers. Thorax 2006; 61: 23-28.

25 Aronson D, Roterman I, Yigla M, et al. Inverse association between pulmonary function and C-reactive protein in apparently healthy subjects. Am J Respir Crit Care Med 2006; 174: 626-632.

26 Olafsdottir IS, Gislason T, Thjodleifsson B, et al. Gender differences in the association between C-reactive protein, lung function impairment, and COPD. Int J Chron Obstruct Pulmon Dis 2007; 2: 635-642.

27 Bonafè M, Olivieri F, Cavallone L, et al. A genderdependent genetic predisposition to produce high levels of IL-6 is detrimental for longevity. Eur J Immunol 2001; 31: 2357-2361.

28 Kathiresan S, Larson MG, Vasan RS, et al. Contribution of clinical correlates and $13 \mathrm{C}$-reactive protein gene polymorphisms to interindividual variability in serum Creactive protein level. Circulation 2006; 113: 1415-1423.

29 Aronson D, Avizohar O, Levy Y, Bartha P, Jacob G, Markiewicz W. Factor analysis of risk variables associated with low-grade inflammation. Atherosclerosis 2008; 200: 206-212. 